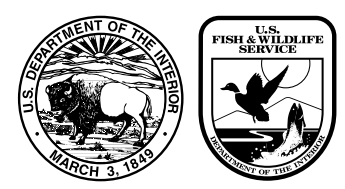

Bull trout are members of the char subgroup of the salmon family (salmonids), which also includes the Dolly Varden, lake trout and Arctic char. Bull trout living in streams grow to about 4 pounds while those in lake or large river environments can weigh more than 20 pounds.

Biologists distinguish char from other salmonids such as trout and salmon by the absence of teeth in the roof of the mouth, the presence of light-colored spots on a dark background (trout and salmon have dark spots on a lighter background), the absence of spots on the dorsal fin, their smaller scales, and differences in skeletal structure. Char species such as bull trout live farther north than any other group of freshwater fish except Alaskan blackfish and are well adapted for life in very cold water.

Bull trout and Dolly Varden look very similar and once were considered the same species. However, taxonomic

\title{
Salvelinus confluentus
}

research has identified them as different species. Both have small pale yellow to crimson spots on a darker background, which ranges from olive green to brown above, fading to white on the belly. Spawning adults develop varying amounts of red on the belly. Both species also exhibit differences in size, body characteristics, coloration, and behavior across their range.

Bull trout are larger than Dolly Varden, with a relatively longer and broader head. Bull trout are mainly an inland species, while Dolly Varden are more common in coastal areas. In Washington State, both species are present in the Puget Sound area.

Historically bull trout occurred throughout the Columbia River Basin; east to western Montana; south to the Jarbidge River in northern Nevada, the Klamath Basin in Oregon, and the McCloud River in California; and north to Alberta, British Columbia, and possibly southeastern Alaska. Today bull trout are found primarily in upper tributary streams and several lake and reservoir systems; they have been eliminated from or their numbers reduced in the main stems of most large rivers. The main populations remaining in the lower 48 states are in Montana, Idaho, Oregon, and Washington with a small population in northern Nevada. Bull trout no longer occur in northern California.

Small bull trout eat terrestrial and aquatic insects but shift to preying on other fish as they grow larger. Large bull trout primarily prey on fish such as whitefish, sculpins and other trout.

Bull trout spawn in the fall after water temperatures drop below $48^{\circ}$ Fahrenheit, in streams with cold, unpolluted water, clean gravel and cobble substrate, and gentle stream slopes. Many spawning areas are associated with cold water springs or

Some bull trout live near areas where they were hatched. Others migrate from streams to lakes, rivers, or salt water a few weeks after emerging from their gravel nests. Migratory bull trout grow larger than resident stream fish.

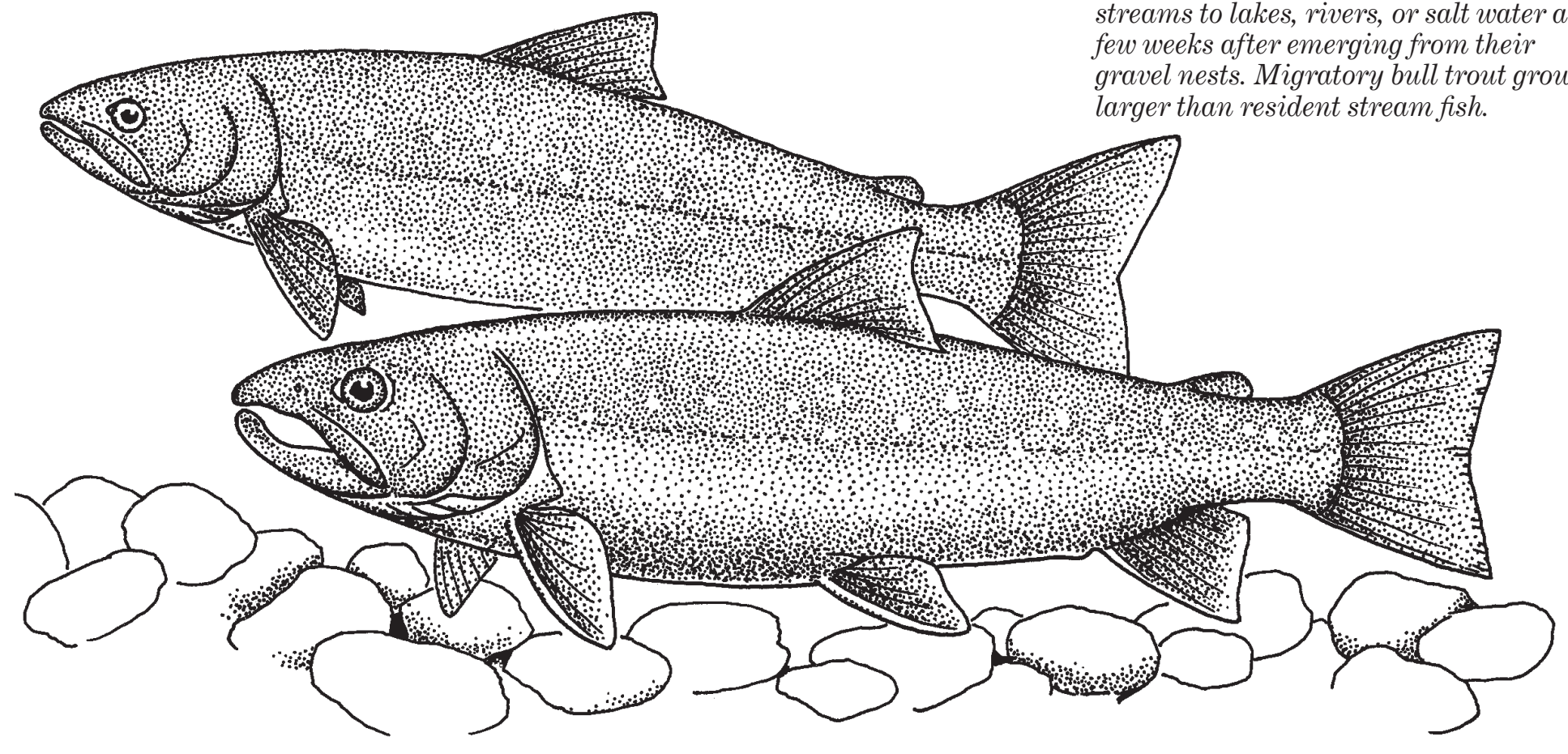


areas where stream flow is influenced by groundwater. Bull trout eggs require a long incubation period compared to other salmon and trout (4 to 5 months), hatching in late winter or early spring. Fry remain in the stream bed for up to 3 weeks before emerging. Juvenile fish retain their fondness for the stream bottom and are often found at or near there.

Some bull trout (resident fish) spend their entire lives near areas where they were hatched. Others migrate from streams to lakes (adfluvial) or rivers (fluvial) or, in the case of coastal populations, salt water, to forage. Because migratory bull trout have more extensive ranges and, consequently, access to more resources, they tend to be larger than resident individuals.

Bull trout are vulnerable to many of the same threats that have reduced salmon populations in the Pacific Northwest. They are more sensitive to increased water temperatures, poor water quality, and low flow conditions than many other salmonids. Past and continuing land management activities such as timber harvest and livestock grazing have degraded stream habitat, especially along larger river systems and stream areas located in valley bottoms, to the point that bull trout can no longer survive or reproduce successfully. In many watersheds, remaining bull trout are small, resident fish isolated in headwater streams.
Brook trout, introduced as a sport fish throughout much of the bull trout's range, often interbreed with bull trout, producing mostly sterile offspring. Nonnative brook trout also reproduce earlier and at a higher rate than bull trout, often supplanting bull trout populations. Dams and other in-stream structures also affect bull trout by blocking migration routes, altering water temperatures, and killing fish as they pass through and over dams or are trapped in irrigation and other diversion structures.

In June 1998, the U.S. Fish and Wildlife Service listed the bull trout in the Columbia and Klamath river basins as threatened under the Endangered Species Act of 1973. An endangered species is considered in danger of extinction throughout all or a significant portion of its range. A threatened species is considered likely to become endangered within the foreseeable future. In April 1999, bull trout in the Jarbidge River Basin were listed as threatened and, in November 1999, they were listed as threatened in the coastal-Puget Sound area of Washington State and the St. Mary-Belly River areas of Montana.

For listing purposes the range of bull trout was broken into distinctive population segments. Bull trout occur in widespread, but fragmented habitats and have several life history patterns. In addition, threats are diverse and the population status and trends vary considerably throughout the range. By examining distinct population segments, bull trout in most need of Federal protection become a listing priority.

Many of the actions intended to protect other declining salmonids may also help bull trout. Stream and habitat protection and restoration, reduction of siltation from roads and other erosion sites, and modification of land management practices to improve water quality and temperature are all important.

The Bull Trout Recovery Team has developed a draft recovery plan providing a framework for implementing recovery actions in the coterminous United States. Because bull trout are widely distributed over a large area and have differing threats, the U.S. Fish and Wildlife Service identified 27 recovery units based on large river basins and generally following existing boundaries of conservation units for other fish species described in state plans, where possible. Each recovery unit has its own individualized recovery strategy. On November 29, 2002, the Service released the introductory chapter and 24 recovery unit chapters for public comment. The remaining chapters, which cover the Jarbidge River and coastal and Puget Sound areas, will be released in October 2003.

More information on this species is available at $<$ http://species.fws.gov/ bulltrout $>$.

\footnotetext{
Bull trout spawn in the fall after water temperatures drop below $48^{\circ}$ Fahrenheit, in streams with cold, unpolluted water, clean gravel and cobble substrate and gentle stream slopes. Bull trout eggs require a long incubation period compared to other salmon and trout (4 to 5 months), hatching in late winter or early spring. Fry remain in the stream bed for up to 3 weeks before emerging.
}

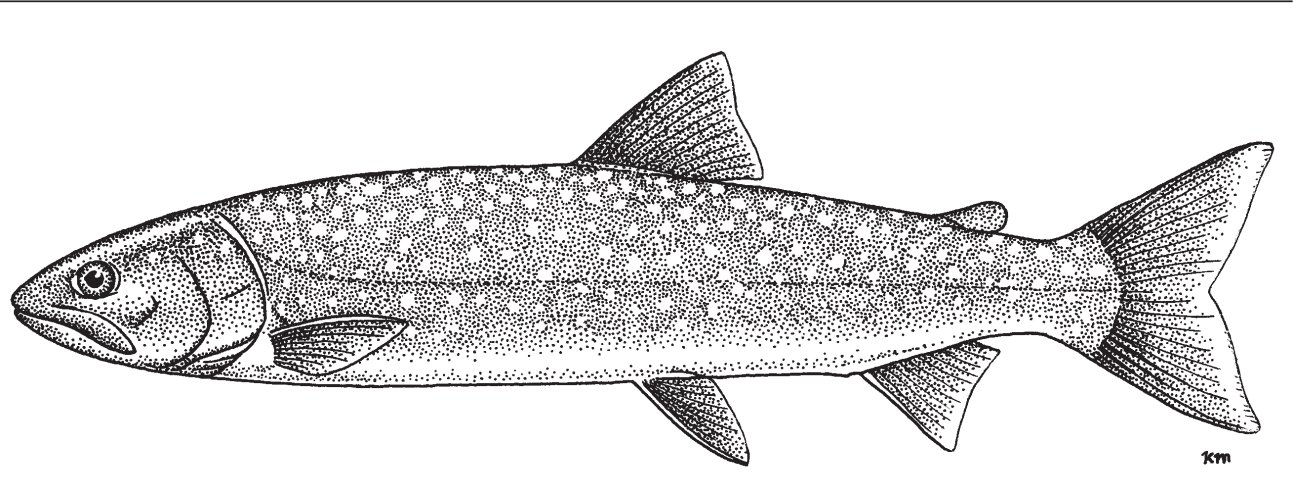

\section{U.S. Fish \& Wildlife Service $1800 / 344$ WILD http://www.fws.gov January 2003}

